\title{
A INTERNET COMO VETOR DO DESENVOLVIMENTO SOCIAL NA CONTEMPORANEIDADE
}

\section{INTERNET AS A VECTOR OF SOCIAL DEVELOPMENT IN CONTEMPORARY TIMES.}

\author{
${ }^{1}$ Pedro Eugenio Pereira Bargiona \\ ${ }^{2}$ Paulo José Pereira Carneiro Torres da Silva
}

\section{RESUMO}

O presente trabalho, ao abordar a temática do desenvolvimento como liberdade, tese proposta pelo indiano Nobel da Economia, Amartya Sen, propõe uma reflexão crítica acerca do papel da Internet enquanto vetor social para persecução das categorias ora propostas pelo supracitado pesquisador. Para tanto, se utiliza da metodologia da revisão bibliográfica, aliada à análise interpretativa legislativa, aos moldes propostos pelo próprio Marco Civil da Internet, bem como 1 metodologia indutiva, afim de analisar e propor reflexões acerca das maneiras pelas quais a Internet e o Marco Civil podem refletir num avanço para o desenvolvimento e a melhora da qualidade de vida.

Palavras-chave: Marco civil da internet, Desenvolvimento, Liberdade

\section{ABSTRACT}

This essay, when addressing the issue of development as freedom, thesis proposed by Indian Nobel Economics Award, Amartya Sen, proposes a critical consideration on the role of the Internet as a social vector for prosecution of the categories being proposed by aforementioned researcher. Therefore, it uses the methodology of literature review, combined with the legislative interpretative analysis, on the lines proposed by the Marco Civil da Internet itself, as well as the inductive method in order to analyze and propose reflections on the ways in which the Internet and the Marco Civil may reflect a breakthrough for the development and improvement of quality of life.

Keywords: Marco civil da internet, Development, Freedom

\footnotetext{
${ }^{1}$ Mestrando em Direito pela Pontifícia Universidade Católica - PUC, São Paulo, (Brasil). Editor Assistente da Revista de Direito da Administração Pública (REDAP-UFF) e da Revista de Direito Constitucional Internacional e Comparado (RDCIC-UFJF). E-mail: pbargiona@gmail.com

${ }^{2}$ Mestrando em Direito Constitucional pela Universidade Federal Fluminense - UFF, Niterói, Rio de Janeiro, (Brasil). E-mail: pauloj.direito@gmail.com
} 


\section{INTRODUÇÃO}

Um João acorda, ao chiado irritante de um smartphone na cabeceira. Resistindo ao impulso de apertar a soneca, percebe que seus amigos tiveram uma noite intensa de diversão ao meio da semana, vendo as fotos no Whatsapp. Checa algumas notícias de seu time, para ter ânimo de levantar-se e fazer sua corrida matinal, sempre com o devido acompanhamento do Runkeeper. Aproveitando o belo dia, declara-se membro da geração saúde através de uma foto no Instagram e volta para casa. Talvez tenha se animado demais, pois, atrasado para o trabalho, é forçado a consultar o Waze para descobrir se há algum caminho sem trânsito. Tem sorte e consegue chegar a tempo para a videoconferência por Skype com seus clientes alemães, que lhes enviam algumas propostas, por escrito. Pelo bem da celeridade, utilizam o Google Tradutor e continuam as negociações até de noite. Mas hoje é sexta e, com o fim do expediente, checa o Tinder e a Lista Amiga para decidir o programa da noite com os amigos. Para não fazer provas da noitada, tira algumas fotos no Snapchat e volta para casa, pois o fim de semana está apenas começando.

A tecnologia e a Internet modificaram permanentemente a forma como os homens se relacionam entre si e com as instituições ${ }^{1}$. Não se trata de apenas de uma leve alteração de formas de socialização anteriores, mas sim da criação, substituição e crise de formas anteriores de relacionamento. Como exemplo, a relação das pessoas com a própria tecnologia é uma novidade para a história, dado que nunca antes houve um acesso tão facilitado à tamanha tecnologia de comunicação; por outro lado, interações consideradas como burocráticas ou perda de tempo, como ir ao banco, são cada vez mais substituídas pelo uso de aplicações online e para celular. Por fim, não se sabe mais, nos dias de hoje, o que é conseguir formulários de imposto de renda ou levar disquetes (os falecidos e não saudosos disquetes) no posto da Receita Federal.

É tamanha a profundidade de nossa relação com a tecnologia e, através dela, com outras pessoas e instituições que não se pode simplesmente imaginar que o que seria adequado ao tempo das correspondências e telegramas será, ainda hoje, perfeitamente cabível, sem modificações, sem adaptações. Direito não escapa a isso, enquanto disciplina científica encarregada pelo regramento saudável da vida em sociedade.

O objetivo deste trabalho é apresentar a realidade tecnológica e seu constante desenvolvimento, comparando-as ao andar do Direito e suas regras. Mais especificame nte,

\footnotetext{
${ }^{1}$ Para uma interes sante reflexão sobre a matéria, recomenda-se a leitura de KRAUT, KIESLER, BONEVA et al. (2002).
} 
aborda-se os possíveis impactos da norma no desenvolvimento de uma comunidade. Normas feitas desmesuradamente, sem levar em conta a existência de diversos atores e especificidades do mercado, certamente gerarão problemas econômicos. De mesma forma, desregular completamente as atividades econômicas também repercute no Direito, posto que a criatividade humana, quando junto da ganância, geralmente resulta em crimes e danos a serem reparados.

Se Direito e Economia caminham juntos, a Tecnologia impulsiona a economia e freia o Direito, tentando e conseguindo afastá-los. Só com a tecnologia foi possível a globalização do mercado, com a divisão internacional do trabalho - pressionando as legis lações trabalhis tas e ambientais locais - e a consideração global dos preços de mercado na produção e venda de produtos. Se hoje uma geada destruir as plantações de trigo da Ucrânia, certamente o pão francês vendido em cada esquina do Brasil ficará mais caro, mesmo que não compremos tanto trigo ucraniano assim. A velocidade que a tecnologia imprime aos negócios e à própria vida cotidiana não combina com a morosidade da Justiça, eivada à sabedoria popular pela máxima "A Justiça tarda, mas não falha". Num mundo em que segundos investidos podem representar milhões a mais ou a menos, anos num processo podem sim representar uma falha, não de decisão, mas de processo decisório.

Existe, contudo, pelo menos um ponto em que Economia, Tecnologia, Justiça e Direito se unem: o Desenvolvimento. Não custa lembrar que o desenvolvimento não é mero crescimento econômico, mas sim o avanço efetivo da qualidade de vida e liberdade das pessoas.

Especificamente, o objetivo deste trabalho é investigar como a Internet e seu Marco Civil se relacionam com uma concepção ampla e holística de desenvolvimento, levando em conta os fatores econômicos e socioculturais do Brasil. Para tanto, buscará não apenas no texto do relatório, mas também nas melhores doutrinas sobre o assunto, embasamento teórico que auxilie na conclusão de uma pergunta fundamental: como a Internet e o Marco Civil podem refletir num avanço para o desenvolvimento e a melhora da qualidade de vida?

Na busca da resposta a esta questão, o trabalho será dividido, estruturalmente, em duas partes: a primeira, intitulada "Contexto e Operação Técnica do Marco Civil da Internet" busca apresentar o contexto da inclusão digital no Brasil, juntamente ao histórico do desenvolvimento do marco jurídico aplicado à Internet no país, identificando interlocutores relevantes, de modo a compreender os riscos que o mesmo mitiga. Para esta finalidade, a metodologia adotada é a revisão bibliográfica e a interpretação legislativa, nos moldes e técnicas propostas pela própria, utilizando a metodologia dedutiva. 
A segunda parte, intitulada "Marco Civil da Internet e Desenvolvimento", busca apresentar os benefícios da existência do Marco Civil através da análise dos seguintes eixos: as Liberdades Políticas e a Democracia no tempo da Internet; as Possibilidades Econômicas e o Empreendedorismo; as Oportunidades Sociais; a Transparência e Publicidade, Intimidade e Privacidade. Para a análise de cada um destes eixos, utiliza-se da revisão bibliográfica e da metodologia dedutiva ou indutiva, analisando disposições legais ou casos concretos que sejam mais relevantes à temática proposta.

\title{
PARTE I: CONTEXTO E OPERAÇÃO TÉCNICA DO MARCO CIVIL DA INTERNET
}

\section{A. O Accesso à Internet no Brasil}

A despeito dos usuários mais apressados, o acesso à Internet no Brasil foi realmente impulsionado por duas experiências: a primeira, dos pontos de cultura ${ }^{2}$ - "entidades reconhecidas e apoiadas [...] pelo Ministério da Cultura que desenvolvem ações de impacto sociocultural em suas comunidades"3 - geralmente situadas em áreas de baixa-renda. A iniciativa mostrou que, apesar da localização,

\begin{abstract}
"muitas das ideias e práticas que nele circulam (ou puderam circular) conectam-s e ao que existe de mais complexo na discussão sobre inovação no mundo de hoje. [...] Tratam-se de tópicos como o software livre, o Creative Commons, a produção colaborativa de conteúdos, o ativismo hacker, a cultura da gambiarra enquanto criatividade genuinamente nacional, a reciclagem de tecnologias obsoletas e do lixo digital, assumindo novos usos, a liberdade para entender, modificar e aperfeiçoar os produtos de consumo derivados do mundo digital, tanto no hardware quanto no $\mathrm{s}$ oftware". (LEMOS,2011, PP. 10-11)
\end{abstract}

A segunda experiência, conjuntamente à primeira, deu-se com as lan houses, que ocupam até hoje a posição de alguns dos principais pontos de acesso à Internet no Brasil, em especial na parte mais baixa da pirâmide social $^{4}$, sendo um negócio geralmente familiar e facilmente encontrado ${ }^{5}$. As lan houses nasceram exatamente da necessidade de acesso para as pessoas mais pobres, incapazes de arcar com os altos custos dos equipamentos e da conexão com a Internet do Brasil, uma das mais caras do mundo (UNCTAD (2011), p. 39, tabela II.7),

\footnotetext{
2 Para um estudo mais aprofundado do funcionamento do programa, ver FERRAZ, CABRAL e MAGRANI (2011)

3 Definição dada pelo Ministério da cultura, disponível em: <http://www.cultura.gov.br/culturaviva/ponto-de-



$439 \%$ dos que ganham até $1 \mathrm{SM}$ acessam por centros públicos de acesso pago, como lan houses. $42 \%$ das classes D e E também o fazem. http://cetic.br/us uarios/tic/2011-total-bras il/rel-int-04a.ht m (acesso em: 14 jul 2015)

5 CETIC (2010), p. 17. Também se aponta que apud LEMOS (2011), p. 13, a Associação Brasileira de Centros de Inclus ão Digital estima a existência de 108 mil lan houses no país, ao passo que só haveria 5 mil bibliotecas públicas, 2200 salas de cinemas ou 2500 livrarias.
} 
e do espirito empreendedor, que, ao ver o programa "Computador para todos" do Governo Federal, enxergou oportunidade de negócio (LEMOS (2011), PP. 13-14) e foi rapidamente alvo de todo tipo de sanção preconceituosa da lei, de maneira completamente desarrazoada e embasando-se em mitos (Ibid. PP. 14-16).

Recentemente, pode-se apontar, com base nos dados recentes do $\mathrm{IBGE}^{6}$, que a popularização dos smartphones se configurará como uma terceira experiência o acesso à Internet no Brasil, dado que quase metade do país já está conectada e há $4 \%$ da população nacional que o faz apenas por meio do celular, sendo esta já a principal forma de acesso na região Norte do Brasil. Mais da metade dos domicílios conectados possui tanto banda larga fixa quanto a móvel, que representa $43,5 \%$ dos domicílios.

\section{B. A Quem Serve o Marco Civil da Internet?}

Direta ou indiretamente, todos são usuários da Internet. Não há como se pensar o mundo contemporâneo sem as possibilidades e facilidades criadas pela Internet e mesmo aqueles que ainda não se beneficiam diretamente dela estão sob a jurisdição de órgãos que a utilizam. O Marco Civil da Internet, contudo, é focado especificamente em alguns atores: os usuários, os provedores de conteúdo, os provedores de conexão, os provedores de aplicações, os administradores de sistemas autônomos e o Poder Público.

Os usuários são as pessoas que utilizam a Internet, tendo acesso ao conteúdo de sites e aplicações de Internet, definidas pelo Art. 5\%, VII como "o conjunto de funcionalidades que podem ser acessadas por meio de um terminal conectado à Internet”. Hoje em dia, em tempo de uma Internet colaborativa e construída pelo usuário ${ }^{7}$, todo usuário é também um provedor de conteúdo para as aplicações online, como o Facebook.

Provedores de aplicações são as pessoas físicas ou jurídicas que disponibilizam funcionalidades na rede, seja um site sem possibilidade de colaboração do usuário (como o jurássico www.pudim.com.br), um site amplamente colaborativo, como todas as redes sociais são, tais como Facebook, YouTube etc. ou qualquer outro aplicativo que utilize a Internet, como o Whatsapp, o Tinder etc. Estes setores foram particularmente favoráveis ao Marco Civil, pelos

\footnotetext{
${ }^{6}$ http://www.ebc.com.br/tecnologia/2015/04/acesso-Internet-chega-494-da-populacao-brasileira (acesso em 17 jul 2015)

${ }^{7}$ Este conceito é conhecido como Web 2.0, ou "Web como plataforma" e foi cunhado por Tim O'Reilly, fundador da O'Reilly Media, quando da organização de uma série de conferências sobre o tema. Foi, na verdade, a constatação de algumas caracterís ticas das empresas de Internet que conseguiram sobreviver à bolha da Internet. A respeito, confira-s e : http://www.oreilly.com/pub/a/web2/archive/what-is-web-20.html (acesso em 17 jul 2015).
} 
princípios e provisões estabelecidas, como a responsabilidade mediata por conteúdo gerado por terceiros ${ }^{8}$.

Provedores de conexão à Internet, de que trata o Art. 14, são pessoas físicas ou jurídicas que prestam o fornecimento de conexão com a Internet, definida pelo Art. $5^{\circ}, \mathrm{V}$, como "a habilitação de um terminal para envio e recebimento de pacotes de dados pela Internet, mediante a atribuição ou autenticação de um endereço IP”. Distinguem-se grandemente dos administradores de sistemas autônomos (ou, na sigla inglesa ISP - Internet Service Provider) que são as empresas de telecomunicação autorizadas pela ANATEL e que, nos termos do Art. $5^{\circ}$, IV "administra blocos de endereço IP específicos e o respectivo sistema autônomo de roteamento, devidamente cadastrada no ente nacional responsável pelo registro e distribuição de endereços IP geograficamente referentes ao País”. Exemplo de provedor de conexão é uma lan house, enquanto um exemplo de administrador de sistema autônomo são a VIVO, NETVirtua etc.

Estas últimas, conhecidas como "teles", formaram o principal lobby contrário ao Marco Civil da Internet por conta da neutralidade de rede, ou seja, a obrigação de tratar igualmente todos os pacotes de dados, o que impossibilita o que seus representantes chamam de "novos modelos de negócios", consistindo na possibilidade de tarifar diferentemente dados oriundos de diferentes origens em função de sua natureza e volume. Assim, sites como o YouTube e Facebook poderiam ser cobrados separadamente e com tarifas diferenciadas; quem não pagar estas tarifas poderia ter seu acesso degradado ou até mesmo restrito (GROSSMANN, 30/08/2012). Por outro lado, possibilitaria que, na ausência dessa cobrança, alguns serviços que demandem mais banda ou que não admitam atrasos, como o streaming de vídeo e aplicativos torrent, recebessem mais prioridade dos servidores, resultando num serviço melhor ${ }^{10}$.

É importante destacar que, quando das discussões legislativas acerca do Marco Civil, a indústria fonográfica, que no exterior é a principal responsável pelos lobbies que geraram tentativas de leis muito criticadas, como a SOPA (Stop Online PiracyAct), PIPA (Preventing Real Online Threats to Economic Creativity and Theft of Intellectual Property Act), além do ACTA (Anti-Counterfeiting Trade Agreement) e do atual acordo de comércio em negociação

\footnotetext{
${ }^{8}$ Ver TERRA (20/10/2013) e EXAME (25/10/13).

${ }^{9}$ Ver a fala de Eduardo Levy, representante do Sindicato Nacional das Empresas de Telefonia e de Serviço Móvel Celular e Pessoal (SindiTelebras il) no Relatório final do Marco Civil da Internet (BRASIL. CÂMARA DOS DEPUTADOS, 2013, PP. 26-27).

${ }^{10}$ Ver a fala de Demi Getschko, membro do Comitê Gestor da Internet no Brasil (CGI.br) no Relatório final do
} 
TPP (Trans-Pacific Partnership Agreement), no Brasil fizeram propostas e foram atendidas ${ }^{11}$ com dispositivos do Marco Civil, especialmente o Art. 31, o que os posicionou favoravelme nte à $\operatorname{lei}^{12}$.

Art. 31. Até a entrada em vigor da lei específica prevista no $§ 20$ do art. 19, a responsabilidade do provedor de aplicações de Internet por danos decorrentes de conteúdo gerado por terceiros, quando se tratar de infração a direitos de autor ou a direitos conexos, continuará a ser disciplinada pela legislação autoral vigente aplicável na data da entrada em vigor desta Lei.

Por fim, o Poder Público, para fins do Marco Civil, constitui a União, os Estados, o Distrito Federal, os Municípios e também o Ministério Público. A eles a lei estabelece diretrizes, obrigações e possibilidades de atuação em matérias que envolvam a Internet. O governo brasileiro, como se apontou, foi, ao final, grande apoiador do projeto e, apesar de pequenas ressalvas e pedidos de mudanças, aceitou o texto final do Relatório, que se converteu em lei ${ }^{13}$.

\section{Quais Riscos o Marco Civil da Internet Reduz?}

A primeira vantagem de ter uma lei é a garantia de existir um ordenamento legal estável aplicável aos casos que lhe comportem, criando um mínimo de segurança jurídica. O vácuo legislativo que se dá sobre diversas questões permite que conclusões diversas sejam tomadas por interlocutores diferentes utilizando parâmetros, experiências e métodos de interpretação do ordenamento muito diversos, o que cria incertezas e exige do Poder Judiciário custos e esforços para decisão e posterior padronização dos litígios. Ter um Marco Civil da Internet é, sobretudo, uma garantia a todos os atores envolvidos - ou seja, toda a sociedade. Mesmo àqueles que defendem a contrariedade ao ali disposto, existir parâmetro definido de legalidade permite o cálculo de riscos das ações que serão tomadas, criando instrumentos de mercado que garantam ao investidor maior previsibilidade.

A imprevisibilidade dos riscos é um dos maiores obstáculos a qualquer atividade econômica. A crise financeira de 2012, que ainda repercute muito em economias mais fragilizadas, se originou exatamente do que se chama de a economia da incerteza ${ }^{14}$, apostas

\footnotetext{
11 Ver http $/ /$ culturadigital.br/marcocivil/tag/civil -rights-framework-for-Intemet/ (acesso em 17 jul 2015)

12 Sobre este episódio, ver ESTADÃO (3010/2013).

13 Havia em pauta discussões polêmicas sobre a guarda de dados no Brasil, já que o Governo des eja va que a guarda fosse obrigatoriamente feita em território nacional e as empresas alegam que isso não é necessário para que se cumpram as decis ões judiciais . Para mais, ler CRAIDE (31/102013) e MORAES (30/10/2013).

14 A incerteza impede o uso da análise custo-benefício, "uma vez que os custos ou os benefícios (ou ambos) de um dado curso de ação geralmente são probabilís ticos em vez de quantidades determinadas". A ausência de dados objetivos impede a formação de probabilidades objetivas.É importante anotar que a incerteza não impede pessoas de tomarem decisões, mesmo que muitas vezes levadas por uma "probabilidade subjetiva", um vício de
} 
feitas sem respaldo informacional e sem um cálculo de riscos de inadimplência ou não atingimento do fluxo ideal de capital ${ }^{15}$. O dicionário virtual de economia do The Economist remete o vocábulo incerteza (uncertainty) ao vocábulo informação (information), anotando que esta é

\begin{abstract}
"The oil that keeps the economy working smoothly. Economic efficiency is likely to be greatest when information is comprehensive, accurate and cheaply available. Many of the problems facing economies arise from people making decisions without all the information they need. One reason for the failure of the command economy is that government planners were not good at gathering and processing information. Adam Smith's metaphor of the invisible hand is all about how, in many cases, free markets are much more efficient at processing information on the needs of all the participants in an economy than is the visible, and often dead, hand of state planners. Asymmetric information, when one party to a deal knows more than the other party, can be a serious source of inefficiency and market failure. Uncertainty can also impose large economic costs. The Internet, by greatly increasing the availability and lowering the price of information, is helping to boost economic efficiency. But there are inefficiencies the Internet will not be able to solve. Uncertainty will remain a huge source of economic inefficiency. Alas, potentially the most useful information, about what will happen in the future, is never available until it is too late" ${ }^{16}$ (Grifos nossos).
\end{abstract}

A incerteza impede o uso da análise custo-benefício, "uma vez que os custos ou os benefícios (ou ambos) de um dado curso de ação geralmente são probabilísticos em vez de quantidades determinadas" (POSNER, 2012, P. 10). A ausência de dados objetivos impede a formação de probabilidades objetivas.

É importante anotar que a incerteza não impede pessoas de tomarem decisões, mesmo que muitas vezes levadas por uma "probabilidade subjetiva" (Idem), um vício de autoconfirmação, de que suas escolhas tem chance de darem certo, mesmo que tal chance não seja calculável. É assim com a decisão de se casar, cursar uma faculdade entre tantas outras que se tomam com base em vícios de confirmação, de acreditar estar tomando a melhor escolha,

autoconfirmação de que suas escolhas tem chance de darem certo, mesmo que tal chance não seja calculável (POSNER, 2010, p. 10). É as sim com a decisão de se cas ar, curs ar uma faculdade entre tantas outras que se tomam com base em vícios de confirmação, de acreditar estar tomando a melhor escolha, quando na verdade não se analisou todas as vertentes de dados possíveis, nem tampouco todas as consequências. Amartya Sen traz a importante parábola e paradoxo dos três desempregados, ummais pobre, mas mais feliz, um mais triste, mas menos pobre, e outro nem tão pobre nem tão triste, mas doente. Se não se conhecesse as três histórias, ou seja, se a visão estivesse viciada pela confirmação de que um precisaria mais do que os outros, provavelmente se estaria cometendo uma injustiça com os outros dois sem nem se saber disso. Por ser um paradoxo, não se trata de certo ou errado, mas de refletirmos sobre as repercussões implícitas de nossos atos e nos diversos fatores que influenciam numa decisão aparentemente racional (SEN, 2000, PP. 54-55).

15 Para mais sobre a economia da incerteza na atual crise financeira, ler POSNER (2012) e, para um estu do bem mais aprofundado, POSNER (2010).

16 THE ECONOMIST [200-?], vocábulo Information. Disponível em: <http://www.economis t.com/economics -ato-z/i\#node-21529564>. (acesso em 14 jul 2015) 
quando na verdade não se analisou todas as vertentes de dados possíveis, nem tampouco todas as consequências ${ }^{17}$.

Ao mesmo tempo, este mesmo dicionário apresenta o vocábulo Risco como

\begin{abstract}
"The chance of things not turning out as expected. Risk taking lies at the heart of capitalism and is responsible for a large part of the growth of an economy. In general, economists assume that people are willing to be exposed to increased risks only if, on average, they can expect to earn higher returns than if they had less exposure to risk. How much higher these expected returns need to be depends partly on the probability of an undesirable outcome and partly on whether the risk taker is risk averse, risk neutral or risk seeking.

During the second half of the 20th century, economists greatly improved their understanding of risk and developed theories of risk management, which suggest when it makes sense to use insurance, diversification or hedging to change risk exposures.

In financial markets the most commonly used measure of risk is the volatility (or standard deviation) of the price of, or more appropriately the total returns on, an asset. Often added to the risk profile are other statistical measures such as skewness and the possibility of extreme changes on rare occasions." 18
\end{abstract}

Uma forma de se objetivar uma incerteza em um risco é dividir o custo potencial de um evento não provocado por você mesmo pelo custo que seria necessário para evita-lo (Idem). Desta forma, tem-se o mínimo de risco que se corre por não evitar a incerteza. Contudo, esse dado não ajuda em nada na previsão da possibilidade desse risco se concretizar, ou seja, as chances, que não podem ser definidas com as técnicas disponíveis à análise econômica ${ }^{19}$.

A importância desta distinção é fundamental para o desenvolvimento: investimentos arriscados são calculados, sendo feitos por investidores arrojados buscando bons ganhos ou apenas diversificar mais suas áreas de investimento; investimentos inseguros são feitos por especuladores que estão apostando na não concretização do risco ${ }^{20}$, sem tomar medidas para

\footnotetext{
17 SEN (2000), PP. 54-55, traz a importante parábola e paradoxo dos três desempregados, um mais pobre, mas mais feliz, um mais triste, mas menos pobre, e outro nem tão pobre nem tão triste, mas doente. Se não se con hecesse as três histórias, ou seja, se a visão estivesse viciada pela confirmação de que um precisaria mais do que os outros, provavelmente se estaria cometendo uma injustiça com os outros dois sem nem se saber disso. Por ser um paradoxo, não se trata de certo ou errado, mas de refletirmos sobre as repercussões implícitas de nossos atos e nos diversos fatores que influenciam numa decisão aparentemente racional.

18 THE ECONOMIST [200-?], vocábulo Risk. Disponível em: http://www.economis t.com/economics -a-toz/r\#node-21529781. (acesso em 14 jul 2015)

${ }^{19}$ Parece oportuna a analogia à célebre frase atribuída a Galileu "Mensure o que for mensurável e faça mensurável o que não o for". O mes mo se aplica à técnica para a análise econômica em relação à chance de concretização do ris co.

${ }^{20}$ POSNER (2010), PP. 291-300 explica a racionalidade dessa decisão.
} 
prevenir sua ocorrência ${ }^{21}$, sendo possivelmente seguidos por outros, num efeito manada, e, consecutivamente, resultando na formação de uma bolha ${ }^{22}$.

A insegurança, contudo, não se dá apenas sobre índices econômicos. De fato, com a Internet e a grande quantidade de dados a que estamos expostos na economia informacional, até um pequeno investidor poderia conseguir dados suficientes para que possa calcular os riscos de alguma decisão econômica. Estas previsões, contudo, não são completas, pois não levam em consideração o fator político e humano que influenciam grandemente os investimentos. A maior dificuldade de se investir em um mercado fechado, antidemocrático e personalista não necessariamente se relaciona com os indicadores econômicos, mas sim com a imprevisibilidade humana que incidente (SEN, 2000, P. 16).

A segurança jurídica é um tipo de imprevisibilidade humana e nasce da falta de legis lação, pelo descumprimento da existente e pela vagueza interpretativa, que acaba deixando ao juiz a difícil tarefa de decidir sobre o vácuo normativo. A instabilidade na aplicação do direito se coloca sim como um obstáculo importante para os investimentos no País a termos de infraestrutura - inclusive a de rede, dificultando e encarecendo o acesso à Internet - e de produtos e serviços, empobrecendo nosso mercado e criando um inoportuno oligopólio de serviços de péssima qualidade, rendendo até mesmo punições ${ }^{23}$.

Em suma, existem empresários dispostos a tomar riscos grandes, mas eles precisam saber o quão grande são seus riscos. A ausência, instabilidade ou vagueza das normas e políticas públicas impossibilita o Risk Measurement adequado, visto que a falha em um componente de um investimento pode acarretar na contaminação de todo o setor e, dependendo da escala, de toda a economia global. Mesmo que não fosse possível reduzir os riscos (o que não é o caso), é fundamental que seja possível prevê-los.

É inegável que o Marco Civil da Internet reduz os riscos negociais para toda a sociedade. Ao estabelecer explicitamente os direitos e deveres dos diversos atores, em especial a neutralidade de rede e a manutenção da qualidade de acesso, geram-se legítimas expectativas

\footnotetext{
${ }^{21}$ Há muita discussão acerca do que se pode fazer acerca dos ris cos e danos incertos. No direito ambiental, cunhou- $s$ e o polêmico Princípio da Precaução, com gênese na década de 70 na Alemanha, baseando -se não na noção da aus ência de riscos, mas na redução de potenciais danos gerados da incerteza científica acerca dos mesmos. Para uma importante análise sobre este princípio, ver ANTUNES (2011), PP. 31-51.

22 Para mais sobre a formação das Bolhas financeiras, ler HARRAS e SORNETTE (2011).

${ }^{23}$ Posta-se extremamente relevante a este tema a suspensão da venda de chips para três operadoras em diversos estados da federação e as outras punições aplicadas a outras operadoras . Mais informações estão disponíveis em: <http://www.anatel.gov.br/Portal/exibirPortalPagina EspecialPes quisa.do?acao=\&tipoConteudoHtml=1\&codNoti cia=26085>. Acesso em 30/07/2012.
} 
de redução e pacificação de conflitos acerca da comunicação pela rede, facilitando a criação de um melhor ambiente negocial para usuários/consumidores e provedores de aplicações/fornecedores. É o caso, por exemplo, da responsabilidade mediata e decorrente de descumprimento de decisão judicial, para o caso de dano por conteúdo gerado por terceiros.

\section{PARTE II: MARCO CIVIL DA INTERNET E DESENVOLVIMENTO}

\section{A. Quais Benefícios o Marco Civil da Internet Traz?}

O risco, contudo, não é o único fator econômico relevante. O consumo é o principal motivo existencial de qualquer produto ou serviço, dependendo da disponibilidade de volumes de crédito para sua circulação. O mesmo crédito é fundamental para que as empresas possam se manter em funcionamento, não só pela existência do consumo, mas também pela possibilidade de planejarem suas contas de maneira mais adequada. Numa economia integrada e globalizada questões, como a geração de empregos com remuneração justa e garantia de direitos trabalhistas, tais como a possibilidade de sindicalização como forma de reduzir a disparidade de poder entre funcionários e patrões, misturam-se com questões da efetivação dos direitos sociais, como a capacitação pela educação em todos os níveis, desde a educação infantil até a superior, a existência de creches para atender às necessidades dos mais novos, bem como a de casas de repouso para os mais velhos, atendendo assim a seus responsáveis, que precisam trabalhar e a existência de uma previdência social que possa reduzir a dependência do trabalhador para com seu trabalho e possibilite a aposentadoria.

Não há como desligar a efetivação dos direitos sociais da existência de um mercado empresarial livre e competitivo, gerando empregos e impostos. Da mesma sorte, não há como imaginar, hodiernamente, um mercado competitivo sem a influência quase holística da Internet.

Mais que as razões políticas e econômicas dos destinatários identificados, existe uma gama de razões filosóficas e pragmáticas para uma regulação consagradora da Liberdade na Internet e que tenha como princípio a livre-concorrência. Um desenvolvimento é legítimo enquanto traz felicidade e desenvolve as liberdades pessoais de todos os indivíduos de uma sociedade (SEN, 2000). O ilustre prêmio Nobel de Economia Amartya Sen em sua tese "Desenvolvimento como Liberdade" defende que o desenvolvimento consiste da remoção de diversos tipos de "desliberdades" 24 para que se desenvolva a liberdade formal e material das

\footnotetext{
${ }^{24}$ Tradução livre de "unfreedom" utilizada pelo autor.
} 
pessoas, devendo ser entendidas não só como o que podem, hipoteticamente, fazer, mas também como o que se lhes oportuna fazer ${ }^{25}$.

Sen (Op. Cit. P. 10 e 38) apresenta sua análise em cinco liberdades instrumentais: (a) liberdades políticas, (b) possibilidades econômicas, (c) oportunidades sociais e (d) garantias de transparência. A quinta liberdade, seguridade social protetiva, não será tratada por impertinência relativa à matéria ${ }^{26}$. Note-se que esta não é uma divisão, muito menos poderia ser estanque e cada liberdade influencia bastante no nível total de liberdades de um indivíd uo ou sociedade, mas também tem impacto nas outras liberdades elencadas.

\section{B. As Liberdades Políticas e a Democracia no Tempo da Internet}

A primeira de cinco, compreende não apenas o voto em si, mas também a participação democrática nos assuntos administrativos e públicos, bem como no processo legislativo e no controle das políticas públicas (Ibid. P. 38). Essa liberdade deve ser não só possível como materialmente exercível, sendo necessários altos níveis de compreensão do ambiente político, econômico e social bem como alta capacidade comunicativa por todos os integrantes da sociedade. Não é possível dissociar o processo decisório político da esfera pública de discussão ${ }^{27}$ e formar uma opinião baseando-se apenas no noticiado pela grande mídia e sem ao menos a possibilidade de acesso aos dados que servem de base para qualquer opinião. Note-se que a limitação da responsabilidade do provedor de conteúdo na Internet quanto ao conteúdo gerado por terceiros possibilita toda uma gama de novas discussões sem gerar riscos maiores ao gerador do conteúdo inicial.

Nesta seara a Internet tem enorme potencial, possibilitando o acesso a grandes quantidades de informação e opiniões diversificadas, dando ainda o poder de voz a cada pessoa, que pode, criando seu próprio blog, micro blog ou outro meio, expressar-se e angariar audiência para sua opinião, competindo por espaço no mercado público de ideias. O papel da Internet não se restringe, contudo, ao fortalecimento da esfera pública: importantes ferramentas de participação democrática podem ser criadas, fortalecendo uma noção de democracia

\footnotetext{
${ }^{25}$ Esta ideia é desenvolvida por todo o livro, mas fica bem clara na leitura de SEN (2000), pp. 10-11 e 13-14.

${ }^{26}$ Não há ligações claras da Internet com esta liberdade específica, senão as indiretas de aumento de empregos e número de empresas. É claro, contudo, que a criação de plataformas colaborativas e da própria economia colaborativa tem muito a oferecer em termos de oferta e modalidades de seguridade social mais apropriadas aos novos tempos.

27 Para uma análise mais compreens iva da noção de esfera pública juntamente da democracia, ler CALHOUN (1996) e CHARNEY (1998).
} 
deliberativa ${ }^{28}$. No Brasil a pressão por transparência culminou na recente aprovação da Lei $\mathrm{n}^{\circ}$ 12.527/2011, conhecida como Lei de Acesso à Informação, disponibilizando novos dados que auxiliarão nas discussões públicas, ainda que haja, no momento, alguma resistência de setores tradicionalistas. Há ainda o Programa Cultura Viva, que trouxe uma noção de Democracia cultural que poderia ser replicado na Internet ${ }^{29}$.

Outra experiência brasileira de crescente importância é o portal e-democracia da Câmara dos Deputados, pelo qual qualquer cidadão pode fazer suas contribuições para o processo legislativo, tendo suas opiniões lidas e debatidas por outros usuários e, caso o relator julgue oportuno, incorporadas ao relatório final do projeto. O projeto de Marco Civil da Internet passou por esta plataforma, pela qual se implementaram sugestões advindas desde conhecidos estudiosos da área, como Demi Getschko e empresas como Oi, até sugestões feitas pelo Twitter, configurando u m a participação popular sem precedentes num órgão que se considerava uma caixa preta. No exterior, podemos destacar a experiência finlandesa de sociedade da informação local, que contém projetos como a Fábrica de Ideias de Espoo, voltada a incentivar a participação política de jovens de 13 a 20 anos (CASTELLS e HIMANEN, 2007, PP. 172-173), e o caso de Puente Genil, cidade cordobense que recebeu uma pioneira iniciativa de democracia digital (ROBLES, 2008).

O Marco Civil traz em seus artigos $2^{\circ}$ a $4^{\circ}$ que a rede deve servir para a liberdade de expressão e pensamento, a pluralidade e diversidade, o exercício da cidadania, o acesso às informações e conhecimento entre outras previsões que claramente aumentam a liberdade política.

Art. $2^{\circ}$ A disciplina do uso da Internet no Brasil tem como fundamento o respeito à liberdade de expressão, bem como:

I - o reconhecimento da escala mundial da rede;

II - os direitos humanos, o desenvolvi mento da personalidade e oxercício da cidadania em meios digitais;

III - a pluralidade e a diversidade;

IV - a abertura e a colaboração;

V - a livre iniciativa, a livre concorrência e a defesa do consumidor; e

VI - a finalidade social da rede.

Art. $3^{\circ}$ A disciplina do uso da Internet no Brasil tem os seguintes princípios:

I - garantia da liberdade de expressão, comunicação e manifestação de pensamento, nos termos da Constituição Federal;

II - proteção da privacidade;

III - proteção dos dados pessoais, na forma da lei;

\footnotetext{
${ }^{28}$ O uso de serviços de governo eletrônico no Brasil, segundo o CETIC (2011), tabelas G1, G2 ainda é bas tante limitado, tendo sido usado por apenas $31 \%$ das pessoas, sendo a maior parte da utilização para a obtenção de documentos (até 44\%) havendo certa uniformidade na utilização para outros fins desse tipo.

29 Para um aprofundamento no conceito do programa e seus Pontos de Cultura, bem como suas relações com a democracia, ver HOPSTEIN (2011).
} 
IV - preservação e garantia da neutralidade de rede;

V - preservação da estabilidade, segurança e funcionalidade da rede, por meio de medidas técnicas compatíveis com os padrões internacionais e pelo estímulo ao uso de boas práticas;

VI - responsabilização dos agentes de acordo com suas atividades, nos termos da lei;

VII - preservação da natureza participati va da rede;

VIII - liberdade dos modelos de negócios promovidos na Internet, desde que não conflitem com os demais princípios estabelecidos nesta Lei.

Parágrafo único. Os princípios expressos nesta Lei não excluem outros previstos no ordenamento jurídico pátrio relacionados à matéria ou nos tratados internacionais em que a República Federativa do Brasil seja parte.

Art. $4^{\circ}$ A disciplina do uso da Internet no Brasil tem por objetivo a promoção:

I - do direito de acesso à Internet a todos;

II - do acesso à informação, ao conhecimento e à participação na vida cultural e na condução dos as suntos públicos ;

III - da inovação e do fomento à ampla difusão de novas tecnologias e modelos de uso e acesso; e

IV - da adesão a padrões tecnológicos abertos que permitam a comunicação, a acessibilidade e a interoperabilidade entre aplicações e bases de dados.

Além disso, nos artigos 24 e 25, há previsão de mecanismos democráticos de participação, transparência, ampliação do uso e acessibilidade da Internet, promoção da cultura e da cidadania, acessibilidade, além de outros pontos da atuação dos entes públicos. Ainda, prevê-se que a prestação educacional do Estado deve capacitar para, entre outras coisas, a utilização da Internet como ferramenta para o exercício da cidadania. Desta forma, abre caminho para a atuação do Estado de maneira a ampliar a participação democrática.

Art. 24. Constituem diretrizes para a atuação da União, dos Estados, do Distrito Federal e dos Municípios no desenvolvimento da Internet no Brasil:

I - estabelecimento de mecanismos de governança multiparticipati va, transparente, colaborativa e democrática, com a participação do governo, do setor empresarial, da sociedade civil e da comunidade acadêmica; II - promoção da racionalização da gestão, expansão e uso da Internet, com participação do Comitê Gestor da Internet no Brasil;

III - promoção da racionalização e da interoperabilidade tecnológica dos s erviços de governo eletrônico, entre os diferentes Poderes e âmbitos da Federação, para permitir o intercâmbio de informações e a celeridade de procedimentos ;

IV - promoção da interoperabilidade entre sistemas e terminais diversos, inclusive entre os diferentes âmbitos federativos e diversos setores da sociedade;

V - adoção preferencial de tecnologias, padrões e formatos abertos e livres;

VI - publicidade e disseminação de dados e informações públicos, de forma aberta e estruturada;

VII - otimização da infraestrutura das redes e estímulo à implantação de centros de armazenamento, gerenciamento e disseminação de dados no País, promovendo a qualidade técnica, a inovação e a difusão das aplicações de Internet, sem prejuízo à abertura, à neutralidade e à natureza participativa; VIII - desenvolvimento de ações e programas de capacitação para uso da Internet;

IX - promoção da cultura e da cidadania; e

$X$ - prestação de serviços públicos de atendimento ao cidadão de forma integrada, eficiente, simplificada e por múltiplos canais de acesso, inclusive remotos. 
Art. 25. As aplicações de Internet de entes do poder público devem buscar:

I - compatibilidade dos serviços de governo eletrônico com diversos terminais, sistemas operacionais e aplicativos para seu acesso;

II - acessibilidade a todos os interessados, independente mente de suas capacidades físico-motoras, perceptivas, sensoriais, intelectuais, mentais , culturais e sociais, resguardados os aspectos de sigilo e restrições adminis trativas e legais;

III - compatibilidade tanto com a leitura humana quanto com o tratamento automatizado das informações ;

IV - facilidade de uso dos serviços de governo eletrônico; e V - fortalecimento da participação social nas políticas públicas.

Há ainda que se destacar que a Internet, por seu caráter global, plural e diverso, que o próprio Marco Civil reconhece, tornou-se palco para todo tipo de manifestação e debate político. As eleições presidenciais de 2014 foram marcadas por debates acalorados e deboches das posições políticas esdrúxulas ou métodos discursivos pouco ortodoxos dos candidatos, com montagens, imagens, memes e outras formas de manifestação na Internet. Dois anos antes, a Internet foi a principal ferramenta para a organização dos maiores protestos recentes na história nacional, congregando milhões de cidadãos às ruas para protestar pela melhoria da qualidade de vida no país.

Também por seu caráter global, a Internet passou a ser um novo campo para que táticas violentas de manifestação política seja feita. O Hackativismo ou Cyberterrorismo consiste na utilização de meios e técnicas virtuais para levar posicionamentos políticos a público através de canais que não reverberariam tal conteúdo, empregando, para isso, invasões de sistemas e exploração de brechas de segurança. Não apenas publicando mensagens, como foi feito em invasões a contas de celebridades ou figuras políticas, como o próprio Barack Obama $^{30}$, mas também através do vazamento de documentos sigilosos, como os divulgados pelo Wikileaks, que geram grandes repercussões. Dentre essas repercussões, temos a própria aprovação do Marco Civil da Internet, que foi aprovado em decorrência do vazamento de interceptações de comunicações de órgãos e empresas públicas brasileiras pela NSA.

No Brasil, a Lei $n^{\circ}$ 12.737, de 30 de Novembro de 2012, conhecida como lei Carolina Dieckman, por ter sido criada e aprovada em resposta ao vazamento de fotos íntimas da atriz, regula criminalmente o tipo de "invasão de dispositivo informático", acrescido ao Código Penal pelo Art 154-A.

Art. 154-A. Invadir dispositivo informático alheio, conectado ou não à rede de computadores, mediante violação indevida de mecanismo de segurança e com o fim de obter, adulterar ou destruir dados ou informações sem autorização expressa ou tácita do titular do dis positivo ou instalar vulnerabilidade s para obter vantagem ilícit a: Pena - detenção, de 3 (três) meses a 1 (um) ano, e multa.

\footnotetext{
${ }^{30}$ http://money.cnn.com/ 2013/10/28/technology/barack-obama-twitter-hack/ (acesso em 14 jul 2015)
} 
$\S 1^{\circ} \mathrm{Na}$ mesma pena incorre quem produz, oferece, distribui, vende ou difunde dispositivo ou programa de computador com o intuito de permitir a prática da conduta definida no caput.

$\S 2^{\circ}$ Aumenta-s e a pena de um sexto a um terço se da invasão resulta prejuízo econômico.

$\S 3^{\circ}$ Se da invasão resultar a obtenção de conteúdo de comunicações eletrônicas privadas, segredos comerciais ou industriais, informações sigilosas, assim definidas em lei, ou o controle remoto não autorizado do dispositivo invadido: Pena - reclusão, de 6 (seis) meses a 2 (dois) anos, e multa, se a conduta não constitui crime mais grave.

$\S 4^{\circ}$ Na hipótese do $\S 3^{\circ}$, aumenta-s e a pena de um a dois terços se houver divulgação, comercialização ou transmissão a terceiro, a qualquer título, dos dados ou informações obtidos.

$\S 5^{\circ}$ Aumenta-s e a pena de um terço à metade se o crime for praticado contra:

I - Presidente da República, governadores e prefeitos;

II - Presidente do Supremo Tribunal Federal;

III - Presidente da Câmara dos Deputados, do Senado Federal, de Assembleia Legislativa de Estado, da Câmara Legislativa do Distrito Federal ou de Câmara Municipal; ou

IV - dirigente máximo da administração direta e indireta federal, estadual, municipal ou do Distrito Federal.

Há aqui uma interessante questão sobre os limites criminosos deste confuso tipo penal: todo tipo de invasão não autorizada é crime? Todo tipo de venda de programas que facilitam este tipo de invasão é criminosa? É possível caracterizar o Hackativismo como um crime político?

Entende-se que, com relação à primeira pergunta, nem todo tipo de invasão é, $a$ priori, criminosa. Há especialistas em segurança e empresas de consultoria em segurança da informação que buscam vulnerabilidades em diversos portais de média e grande circulação e, encontrando-as (e quase sempre encontram, das mais variadas complexidades ${ }^{31}$ ), comunicam ao responsável pela aplicação os erros encontrados e oferecendo seus serviços para o conserto. Como advogar que estes Hackers estão cometendo crime, quando sua intenção (dolo subjetivo) não se encaixa ao descrito no tipo legal? Configura-se, assim, a atipicidade da conduta.

Com relação ao Hackativismo, sua tipificação como crime é bastante complexa, dada também a complexidade das atitudes tomadas pelos ativistas, indo desde o compartilhamento de conteúdo protegido por institutos de propriedade intelectual como pressão pela modernização dos modelos de acessibilidade e comercialização, até a divulgação de contas em bancos suíços ${ }^{32}$, passando, evidentemente, pela invasão de aplicações para a divulgação de sua mensagem. Cabe aqui aplicar as mesmas considerações acerca da definição de crime

\footnotetext{
${ }^{31}$ Para abordagem por profissionais do ramo acerca de sua experiência, de maneira divertida e leve, recomenda se o Podcast http://jovemnerd.com.br/nerdcas t/nerdcast-346-hackers-crackers-e-dieckmans / (acesso em 14 jul 2015).

32 Para mais sobre o HSBC leaks, ver http://www.independent.co.uk/news/business/news/hsbc-leaks-qa-a-globalscandal-or-a-s torm-in-a-s wis s-teacup-10034838.html (acesso em 14 jul 2015).
} 
político e crime conexo que se utilizaria a outras hipóteses, como homicídios, furtos e sequestros ${ }^{33}$.

\section{As Possibilidades Econômicas e o Empreendedorismo}

A segunda liberdade deve ser entendida como a capacidade de viver tão bem quanto se queira, utilizando recursos econômicos para o consumo, produção ou troca. Os bens das pessoas dependem de quão bem se administram os recursos pessoais e o acesso ao financiamento de projetos, bem como a disponibilidade de crédito para a gestão corrente, consoante já tratado (SEN, 2000, P. 39). Aqui, novamente, a Internet proporciona boas oportunidades de expansão das liberdades e o Marco Civil contribuirá com a mitigação da responsabilidade civil dos aplicativos, bem como com o melhoramento da segurança Jurídica, como já tratado anteriormente.

Em primeiro lugar, a disponibilidade de informações facilita a gestão dos recursos pessoais, embasando decisões de consumo com as experiências de outros usuários, auxiliando na busca do menor preço e, consequentemente ${ }^{34}$, dando mais eficiência aos ganhos dos trabalhadores, podendo ser aplicados a empresas de todo porte de igual forma ${ }^{35}$. Essa expansão também se reflete no mercado acessível, tornando consumidores e empresas atores potenc iais do comércio internacional ${ }^{36}$.

Em segundo lugar, é possível iniciar desde pequenos negócios na Internet e ter ganhos complementares, até tornar a Internet seu negócio principal através do fornecimento de produtos - especialmente os culturais - e serviços em rede. Em terceiro lugar o crowdfunding, ou financiamento pelas massas, em tradução livre, possibilita que milhares de pessoas suportem um projeto ou ideia que acreditem ser interessante apenas pelo prospecto de terem o produto num futuro próximo ou por pequenas recompensas, como a menção de seus nomes.

A falta de certeza sobre o sucesso ou qualidade do produto e mesmo a falta de modelos negociais e outros pré-requisitos básicos para conseguir um financiamento de uma firma de venture capital, por exemplo. Não existem estudos e análises econômicas substanciais a esse

\footnotetext{
33 Para um estudo jurisprudencial acerca do entendimento de crime político na Suprema Corte brasileira, ver http://www.s bdp.org.br/arquivos /monografia/168_Mo nografia\%20Ivan\%20de\%20F ranco.pdf (acesso em 14 jul 2015).

$3486 \%$ dos indivíduos que acessam a Internet no Brasil, a utilizam para a busca de informações sobre bens e serviços (65\%) e contratação de serviços. CETIC (2011), tabelas C7 e C8.

35 GHOSH (1998), apesar de não ser tão recente, faz uma boa análise de possíveis usos da Internet para empresas.

${ }^{36}$ REUBER e FISCHER (2011) traz uma interessante visão sobre as vantagens dessa atuação para empresas.
} 
respeito, mas o site (e empresa online) de consultoria em crowdfunding Douw\&Koren aponta que alguns projetos já romperam a marca do um milhão de dólares ${ }^{37}$, tendo um arrecadado mais de 10 milhões de dólares ${ }^{38}$. Certamente com um capital de kickstart de grande porte como este será fácil conseguir apoio logístico e financeiro suplementar, além de crédito para a gestão, posto que o interesse é tão grande que pessoas pagaram pelo produto sem saber quando receberão.

Governos e empresas já adotam a Internet como forma de seleção de projetos para inovação. É o caso de programas como o A Strategy for American Innovation: securing our economic growth and prosperity da Casa $\mathrm{Branca}^{39}$, que seleciona projetos de interesse nacional dos Estados Unidos para financiamento estatal.

Com relação ao Comércio Eletrônico, o mesmo vem tendo crescimento constante, independentemente da situação do varejo regular ${ }^{40}$. No Brasil, foi editado pela Presidência da República o Decreto $n^{\circ} 7.962$, de 15 de março de 2013, que regulamenta o Código de Defesa do Consumidor para as relações de comércio eletrônico. Suas disposições tratam do acesso a informações básicas da empresa, do produto, do preço e das condições da oferta, trazendo também regulação para as compras coletivas, para o atendimento ao consumidor do comércio eletrônico e regulamentando o direito de arrependimento.

A bem da verdade, alguns observadores apontam o nascimento de toda uma nova modalidade econômica, a que foi dado o nome de Economia Colaborativa (Sharing Economy). Trata-se da utilização da tecnologia da informação para permitir que os usuários utilizem de maneira mais eficiente seus recursos. Exemplos desta economia são o compartilhamento de bens através de empréstimos ou aluguéis, inclusive de quartos e casas, como no caso da AirBnB, a possibilidade de venda de bens usados, reciclados ou reparados, como pelo indexador de Sebos EstanteVirtual, outros sites de anúncios como o Craiglist ou mesmo por grandes empresas, como o SouBarato do Submarino, que revende produtos, devolvidos ou com pequenos defeitos, com grandes descontos.

\footnotetext{
37 Os dados encontram-s e um pouco desatualizados, não incluindo, por exemplo, o projeto de console de jogos independentes OUYA. Ver mais em: <http://www.douwenkoren.nl/en/infographic-million-dollar -crowd funding projects/>. (acesso em 14 jul 2015)

${ }^{38}$ Trata-se do relógio Pebble, que se conecta ao seu smartphone para apresentar informações como mensagens de texto, 0 id de chamadas recebidas entre outras funcionalidades. Mais detalhes em <http://www.kicks tarter.com/projects /597507018/pebble -e-paper-watch-for-iphone-and-android>. (acesso em 14 jul 2015)

${ }^{39} \mathrm{https}: / /$ www.whitehous e.gov/innovation/s trategy (acesso em 14 jul 2015)

40 http://img.ebit.com.br/webs hoppers/pdf/31_webs hoppers.pdf (acesso em 14 jul 2015)
} 
Há um fomento de um estilo de vida em que o compartilhamento de informações entre todos os usuários, de maneira a facilitar o processamento do big data torne a vida de todos eles melhor, como o caso do indispensável Waze, que agrega informações sobre a situação do trânsito com base na experiência dos usuários, redirecionando-os para vias menos congestionadas em tempo real. Governos começam a entender que a tendência criada pelo barateamento do processamento móvel de dados, com a popularização dos smartphones, é um movimento irrefreável de modificação dos padrões de consumo e buscam agora estuda- $\mathrm{l}^{41}$.

Há ainda empresas e aplicações que desafiam as indústrias tradicionais, oferecendo serviços melhores, mais transparentes e mais baratos. São o caso do Spotify, do Popcorn Time, do $A i r B n B$ e do Uber, que desafiam os serviços tradicionais de fornecimento de mídia, no caso dos dois primeiros, de hospedagem e turismo, no terceiro, e de transporte urbano, no último. Tais empresas são constantemente acusadas de fomentar a ilegalidade, a informalidade, a sonegação de impostos e até a discórdia social simplesmente por oferecerem o serviço pelo qual usuário gostaria de pagar.

Sob a ótica do Marco Civil, parece claro que estes modelos de negócio são extremamente alvissareiros. A "liberdade dos modelos de negócios promovidos na Internet, desde que não conflitem com os demais princípios estabelecidos nesta Lei” é um dos princípios do Marco Civil, juntamente dos fundamentos na "a abertura e a colaboração" e "livre iniciativa, a livre concorrência e a defesa do consumidor".

Por outro lado, a Internet também cria oportunidade para modelos de negócio muito menos desejáveis nascerem e se proliferarem. Sequer é necessário recorrer a sites ofuscados, criptografados e escondidos sob protocolos complexos e obscuros para encontrar negócios altamente controversos e potencialmente ilegais ${ }^{42}$. O mais recente exemplo de negócio potencialmente ilegal na rede se deu com o vazamento de dados do Hacking Team, empresa italiana especializada em espionagem, interceptação e violações de segurança para invasões de sistemas e usuários em geral. Se parece óbvio que esta atividade é ilegal, nos termos do Art. 154-A, $\S 1^{\circ}$, do CP, constituindo, portanto, crime organizado a criação e representação de uma

41 http://www.techworld.com/news /startups/uk-government-s ets-up-action-group-help-s haring-economyblossom-3619342/ (acesso em 14 jul 2015)

42 É evidente que iniciativas como a Silk Road, finado site da chamada Deep Web, disponibilizado sob a plataforma TOR com o intuito de vender drogas, são ilegais, configurando -se nas legislações penais aplicáveis ao tráfico de drogas, que, aparentemente, também notou o potencial de lucratividade da Internet. 
empresa como essas no Brasil, às autoridades policiais e de inteligência brasileiras não parece ter ficado tão evidente esta relação criminosa ${ }^{43}$.

Sob a ótica do Marco Civil, contudo, impõe-se a defesa da legalidade deste tipo de empreendimento. O Marco Civil não impede a interceptação de dados, apenas a limita às pessoas e aos casos autorizados em lei. Se há, portanto, demanda pela possibilidade de espionagem e interceptação, é lícito que haja empresa fornecendo este tipo de serviço. A má utilização destes programas, analogamente, é como a utilização de uma arma de fogo para matar uma pessoa: é uma situação provavelmente antijurídica, mas que possivelmente é justificável legalmente no caso concreto.

\section{As Oportunidades Sociais}

A terceira liberdade trata das oportunidades sociais, referindo-se à educação, saúde pública e outros direitos sociais que influenciam a possibilidade de viver mais e melhor, seja diretamente, impedindo a morte precoce, ou indiretamente, atuando sobre as escolhas feitas no campo das duas primeiras liberdades (SEN, 2000, P. 39). Nesta seara, a Internet mostra um grande potencial ainda pouco explorado e concretizado. Já existem experiências com metodologias de ensino à distância e por vídeo, como o Telecurso 2000, desenvolvido para a diminuição da defasagem idade-ano, Educação de Jovens e Adultos e alternativa ao ensino regular em municípios distantes. A metodologia consiste basicamente em tornar o aprendizado algo fluido e interessante, utilizando dos recursos que a edição de imagens permite.

Outras iniciativas de programas educacionais, como o "Mundo de Beakman" também foram bem-sucedidos em despertar e atiçar a curiosidade de crianças e jovens. Mais recentemente um programa bastante parecido, o "Manual do Mundo", feito para o YouTube, tem feito bastante sucesso, já tendo ultrapassado as 564 milhões de exibições e as 3,6 milhões $\operatorname{assinaturas}^{44}$. A pergunta natural da apresentação de tais dados é: por que não utilizar a Internet e a experiência metodológica da distância e atiçamento do interesse, aliado a plataformas como o Moodle, que permite a avaliação e o acompanhamento dos alunos por tutores, para aperfeiçoar

\footnotetext{
43 https://medium.com/io -publishing/o-que-o-vazamento-da-hacking-team-pode-revelar-sobre-a-espionag e m\%C3\%A0-bras ileira-d1e 725855b98 e http://partidopirata.org/hackingteamleaks -abin-compromete-s eguranca nacional-em-acordo-de-es pionagem-digital/ (acesso em 14 jul 2015)

${ }^{44}$ Ademais, o CETIC (2011), tabelas C13 e C14, aponta que $67 \%$ das pessoas que acessam a Internet a utiliza $\mathrm{m}$ para educação, seja pesquisas escolares (59\%) ou até fazer cursos on-line (15\%).
} 
- e muito - o já bom modelo do Telecurso 2000? Os potenciais são enormes e certamente não se restringem a esta propositura ${ }^{45-46}$.

Há também iniciativas educacionais voltadas para a complementação da educação tradicional, que se cega às necessidades do mundo contemporâneo. Portais de educação como a Khan Academy possuem um material didático, interativo, atualizado e, principalmente, diversificado, abordando desde o básico da matemática e das ciências, até artes e humanidades e computação e programação - conteúdos que não integram a grade curricular regular. Também sobre programação, diversos sites, como a hora do código ${ }^{47}$ trazem iniciativas para ensino da programação desde a primeira infância até a terceira idade, abrangendo desde o básico da lógica de programação, utilizando blocos e não texto, até o aprendizado direto e específico de linguagens comuns, como javascript.

Para o aprendizado de línguas também há úteis ferramentas, como o curso básico de LIBRAS online e gratuito da Prime Cursos e o Duolingo, uma premiada plataforma gratuita para o estudo de inglês, espanhol e francês. O próprio Governo Federal se rendeu às grandes possibilidades de ensino de línguas pela Internet e criou o My English Online - MEC, um curso de inglês online para o programa Inglês sem Fronteiras, em associação do MEC e da CAPES. Há ainda iniciativas como o Coursera, para cursos grátis e online, e plataformas de ensino online gratuito de grandes universidades brasileiras, como a USP. As possibilidades ainda estão começando a ser exploradas e certamente ainda há muito espaço para a utilização das ferramentas online para a universalização do conhecimento.

No campo da saúde pública, cirurgias remotas, nas quais o cirurgião pode estar em qualquer lugar do mundo com um terminal, se tornarão mais acessíveis e comuns apenas com conexões estáveis de Internet e o avanço do maquinário. Além disso, prontuários médicos e históricos de doenças poderão ser compartilhados entre os médicos de maneira rápida, em especial nas emergências, em que as decisões são tomadas rapidamente, muitas vezes sem tempo para testar hipóteses. Ambos os usos também dependem do resguardo da privacidade do paciente, que não pode ver seus dados interceptados e coletados por nenhum provedor de serviço ou conexão, sob pena de exposição exacerbada de sua intimidade e vida privada, garantida na Constituição.

\footnotetext{
${ }^{45}$ Sugere-se a leitura de VENCATESAN (2006) para algumas utilizações recentes da EAD.

${ }^{46}$ ASIMOV (1988), em entrevista ao TV World of Ideas da rede americana PBS, mostra magistralmente sua visão de como seria o futuro, incluindo a educação.

47 http://hourofcode.com/br (acesso em 14 jul 2015)
} 
Há ainda um outro ponto fundamental de criação de oportunidades sociais a grupos excluídos: a acessibilidade a pessoas com necessidades especiais para leitura ou locomoção. A existência de iniciativas e alternativas virtuais certamente auxilia sobremaneira a vida de pessoas com dificuldade de locomoção. Já no caso de pessoas com dificuldade de leitura, por razões de perda de visão, a disponibilização de conteúdo legível por programas de computador T2S (Text to speech), através da transformação de caracteres em imagem para códigos legíve is por programas OCR (Optical Character Recognition) é uma revolução na acessibilidade para este público, que pode, autonomamente, ler, escrever, assinar, estudar, compreender e exercer seus direitos de cidadão.

Nesta seara, há uma triste resistência à acessibilidade na seara judicial brasileira. A implantação do Processo Judicial eletrônico, principalmente através da plataforma unificada do PJe, não possui as condições de acessibilidade necessárias para que os atores processuais cegos tenham autonomia e acesso, não permitindo ou utilizando por padrão as tecnologias OCR e T2S. Tal problema grave de planejamento e implantação foi denunciado pela advogada cega Deborah Prates que, em petição ao Conselho Nacional de Justiça, requisitou o direito de protocolar petições e documentos em papel até que a acessibilidade fosse possível, tendo seu pedido negado pelo então presidente, o Min. Joaquim Barbosa ${ }^{48}$. Tal decisão foi duramente criticada pela sociedade e órgãos relacionados à adminis tração da justiça, como a $\mathrm{OAB}^{49}$ e foi ecoada por magistrados com problemas de cegueira ${ }^{50}$, sendo revertida pelo presidente posterior, o Min. Ricardo Lewandowski ${ }^{51}$, não sem uma lamentável e dispensável crítica do anterior presidente ${ }^{52}$.

Sob a ótica do Marco Civil da Internet é mais do que evidente que é direito do usuário a acessibilidade aos sistemas. Desde o Art. $4^{\circ}, \mathrm{IV}$, com objetivos, até as diretrizes para o Poder Público, no Art. 25, II, o Marco Civil é claro em apontar como direito fundamental do usuário a acessibilidade, nos termos do Art. $7^{\circ}$, XII.

Art. 4o A disciplina do uso da Internet no Brasil tem por objetivo a promoção: (...)

\footnotetext{
48 http://www.conjur.com.br/2014 -jan-07/cnj-nega-peticao-papel-advogada-cega-nao-usar-pje (acesso em 14 jul 2015).

49 http://www.oab.org.br/noticia/27692/deu-no-o-globo-uma-advogada-cega-poe-o-dedo-na-ferida (acesso em 14 jul 2015).

${ }^{50} \mathrm{http} / /$ www.s tf.jus.br/portal/cms /verNoticiaDetalhe.as p?idConteudo=272354 (acesso em 14 jul 2015)

51 http://agenciabras il.ebc.com.br/direitos -humanos/noticia/2014-08/deficientes -visuais-nao-cons eguem-usarprocesso-judicial-eletronico (acesso em 14 jul 2015).

52 http://www1.folha.uol.com.br/poder/2014/02/1410224-barbosa-critica-le wandows ki-por-liminar-a -favor-d eadvogada-com-deficiencia-vis ual.shtml (acesso em 14 jul 2015).
} 


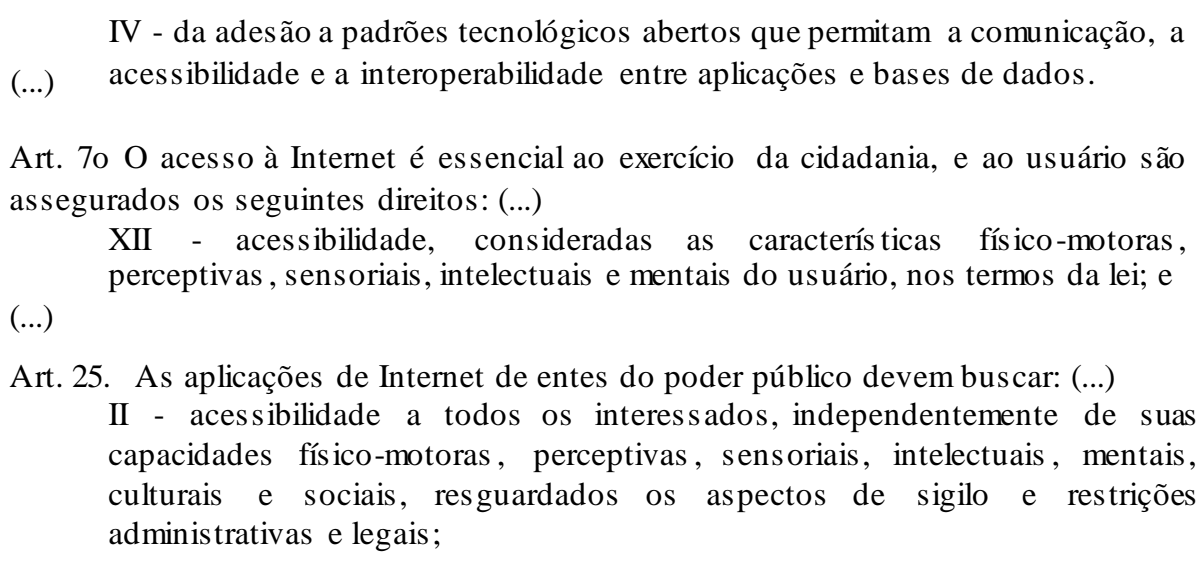

Tanto na hipótese da educação, quanto da saúde, o Marco tem muito a contribuir direta e indiretamente. Diretamente, para a Educação, com a previsão da inclusão do bom uso da Internet, de maneira segura, consciente, responsável, promovendo a cultura, cidadania e o desenvolvimento tecnológico no papel educacional Estado com o Art. 21. Para a Saúde, com as garantias de qualidade e estabilidade de serviço, sem possibilidade de degeneração, senão em casos específicos e delimitados, e com a limitação da guarda de registros pelos provedores de acesso e de aplicativos. Indiretamente para ambos, da mesma forma que influencia o econômico, pois, com segurança jurídica, os investimentos em tecnologia e infraestrutura se tornam mais tangíve is e acessíveis.

\section{E. TRANSPARÊNCIA E PUBLICIDADE, INTIMIDADE E PRIVACIDADE}

A quarta liberdade diz respeito às garantias de transparência, importante sustentáculo da confiança nas instituições públicas. Tudo que se passa no âmbito público deve ser o mais aberto o possível para que, na ocorrência de problemas, possam-se traçar motivos e encontrar responsáveis. A mera exposição é suficiente para evitar o avanço da corrupção, irresponsabilidade financeira e negociatas. A Internet possibilita a disponibilização de grande quantidade de informações à apreciação pública, como com a Lei de Acesso à Informação e do Wikileaks.

O Acesso à Informação pública estava previsto na Constituição Federal, em seus artigos $5^{\circ}$, XXXIII; $37, \S 3^{\circ}$, II, e 216, $\S 2^{\circ}$. Este direito foi positivado através da Lei 12.527 , de 18 de Novembro de 2011, a Lei de Acesso à Informação, regulamentada pelo Decreto $n^{\circ} 7.724$, de 16 de maio de 2012. Genericamente, os instrumentos criados por estes instrumentos legislativos dão a qualquer cidadão o acesso a qualquer informação pública ou sobre a gestão pública, desde que não vinculada à segurança nacional. 
O Marco Civil da Internet como proposto traz como princípio a proteção da privacidade e como objetivo o acesso à Informação e participação nos assuntos públicos. Dispõe também como direito a inviolabilidade da comunicação pela Internet, salvo por ordem judicial, limita a guarda de registros por particulares. No polo da transparência também estabelece como diretriz da atuação de entes públicos na Internet a transparência e o intercâmbio de informações.

Uma questão que vem sendo tratada com grande polêmica diz respeito ao Direito ao esquecimento. Por definição, o direito a ser esquecido tem relação com o impedimento da perenização de informações impertinentes, irrelevantes ou desatualizadas acerca de fatos passados e que causem aos envolvidos sofrimento. Analogamente, pode-se falar de uma aplicação na esfera civil e da Internet do já disposto pelo Art. 94 do Código Penal, c/c Art. 202, da Lei de Execuções Penais.

Como já tratado anteriormente, é basicamente impossível retirar uma informação da Internet. A partir do momento em que entra na rede, ela passa a ser multiplicada em uma razão muito maior do que a capaz de se rastrear, tornando inviável, posteriormente, a extinção dessa informação ${ }^{53}$. Delegar a provedores de aplicações de Internet, como o Google, a infinita tarefa de dificultar o acesso a determinado tipo de dado certamente viola o Marco Civil da Internet, pois cria responsabilização da aplicação por conteúdo de terceiro.

Contudo, o direito à vida privada dos usuários pode ser respeitado de outra forma: passado o momento de relevância destas informações, caso os dados continuem ou voltem a ser replicados e utilizados de maneira a causar desconfortos ao usuário a eles relacionado, bastaria peticionar judicialmente a exclusão desta nova utilização e a responsabilização dos usuários que violam a vida privada. Todas as pessoas devem ter a possibilidade de se arrepender e se envergonhar dos malfeitos de seu passado. O que não pode existir é a possibilidade de apagar o passado, por mais vergonhoso ou depreciativo que seja. Já nos ensinou "O brilho eterno de uma mente sem lembranças", ao melhor sabor de Freud, que o passado não deve ser esquecido, apenas ressignificado.

\footnotetext{
53 Caso em que fica claro a impossibilidade de lidar com a velocidade de difusão dos dados na rede é o triste episódio conhecido como "The fappening" em que fotos eróticas de diversas atrizes e celebridades foram coletadas e divulgadas através da exploração de diversas falhas de segurança de serviços como o iCloud, da Apple. Até hoje é possívelencontrar, sem dificuldades, estas imagens, a despeito das tentativas de dive rs as destas celebridades de as retirarem da Internet.
} 


\section{CONCLUSÃO}

$\mathrm{Na}$ introdução do presente trabalho foi apresentada uma pergunta: Como a Internet e o Marco Civil podem refletir num avanço para o desenvolvimento e a melhora da qualidade de vida? Após discorrer sobre diversos elementos do desenvolvimento como liberdade, a resposta para esta pergunta não poderia ser outra: a Internet dá às pessoas liberdades impensáveis e isso é a maior oportunidade de desenvolvimento humano já criada na história.

O crescimento contínuo do acesso à Internet é uma tendência até que seja universalizado o acesso. Isto representa que todos terão acesso a diversas possibilidades de qualificação pessoal, aprendizado autônomo, inovação, fomento econômico de empreendimentos, cultura e entretenimento de baixo custo e todas as outras vantagens apresentadas por este trabalho.

O Marco Civil da Internet, só por existir enquanto lei, já é um símbolo de uma vitória : um projeto de iniciativa da sociedade civil organizada, discutido, elaborado e defendido pelos seus usuários contra o lobby de grandes corporações se tornou lei. O processo de feitura do Marco Civil e, agora, de sua Regulamentação, são casos dignos de serem estudados e repetidos em diversos outros campos do saber jurídico e por todas as nações, por ter sido amplamente debatido sem que isso representasse o caos na proposição final, que é uma lei coerente e estruturada.

O Marco Civil oferece uma regulamentação que vai desde os princípios básicos da Internet até provisões técnicas de grande relevância para a garantia do direito de todos os usuários e cidadãos, tais como a inviolabilidade da vida privada, do sigilo das conexões, da neutralidade de rede, da guarda de registros e da responsabilidade mediata judicializada pelo conteúdo ofensivo gerado por terceiros. Ao servir de regulamentação para o assunto, ajuda a dissipar a insegurança jurídica do vácuo normativo e da incerteza acerca da aplicação do Direito, possibilitando que seja feito um estudo mais acertado dos riscos dos investimentos e o consequente aumento dos investimentos, que conseguirão mais investidores.

A Internet possibilita a todos o acesso a diversas informações que podem embasá-los melhor nas decisões que tomam, reduzindo os vícios de confirmação. Além disso, pode configurar uma importante fonte de renda complementar para famílias ou mesmo de capital inicial para negócios e empreendedores. Socialmente, a Internet possibilita a expansão da liberdade de expressão e a grande movimentação do mercado público de ideias. O Marco Civil, ao limitar a responsabilidade por conteúdo de terceiros, possibilita que as discussões se travem 
acerca dos argumentos apresentados sem maiores riscos para o autor. Além disso, a Internet traz importantes oportunidades no campo da educação e da saúde que necessitam da regulamentação do Marco Civil acerca de privacidade e qualidade de conexão para serem ampliadas. A cultura virtual também é reconhecida no projeto e certamente deve ser expandida para possibilitar mais oportunidades de interação social para todos.

Finalmente, a Internet é um grande instrumento para a concretização de direitos humanos e o Marco Civil é um importante instrumento para a concretização de liberdades que melhorarão a qualidade de vida das pessoas, realizando assim novos níveis de desenvolvimento. Desta forma, pode-se concluir pela essencialidade do acesso à Internet como concretização dos direitos da cidadania.

\section{REFERÊNCIAS}

ANTUNES, Paulo de Bessa. Direito Ambiental. 13 ${ }^{\text {a }}$ Ed. Rio de Janeiro: Lumen Juris. 2011. ASCENSÃO, José de Oliveira. Direito da Internet e da Sociedade da Informação. $1^{\text {a }}$ Ed. Rio de Janeiro: Forense. 2002.

ASIMOV, Isaac Yudovich. Interview to TV World of Ideas. Produção de Bill Moylers. [s.1.]: PBS. 1988. Vídeo digital com legenda de tradução livre. Disponível em: $<$ http://www. youtube.com/watch? v=CI5NKP1y6Ng\&feature=youtu.be $>. \quad$ Acesso em $10 / 07 / 2015$.

BELLON, Ricardo Bruning. A internet precisa de um marco civil? São Paulo: Levy e Salomão Advogados. 2012. Disponível em: $\langle$ http://www.levysalomao.com.br/files/temp_ls/Monografia_2_10_Concurso.pdf $>$. Acesso em $10 / 07 / 2015$.

BELISÁRIO, Adriano; LOPES, Juliana. As culturas digitais dos Pontos de Cultura e Lan houses. In: FERRAZ, Joana Varon; LEMOS, Ronaldo (Coordenadores). Pontos de Cultura e Lan houses: estruturas para a inovação na base da pirâmide social. Rio de Janeiro: Escola de Direito do Rio de Janeiro da Fundação Getúlio Vargas. 2011.

BONAVIDES, Paulo. Curso de Direito Constitucional. 26a Ed. São Paulo: Malheiros. 2011. BRASIL. CÂMARA DOS DEPUTADOS. Relatório final do Marco-Civil da Internet. Relator: Dep. Alessandro Molon. Brasîlia: Camara.gov.br. 2013. Disponível em: $\langle$ http://www.camara.gov.br/Internet/Agencia/pdf/relatorio_marcocivil_ultimo.pdf $>$. Acesso em 10/07/2015.

CALHOUN, Craig. Habermas and the Public Sphere. $1^{a}$ Ed. Cambridge: Massachusetts Institute of Technology. 1996.

CASTELlS, Manuel; HIMANEN, Pekka. A Sociedade da Informação e o EstadoProvidência: o modelo finlandês. Lisboa: Fundação Calouste Gulbenkian. 2007. 
CAVAlieRI FILHO, Sérgio. Programa de Responsabilidade Civil. 10 ad. São Paulo: Atlas. 2012

CETIC. TIC DOMICÍLIOS e USUÁRIOS 2011. [São Paulo]: cetic.br. 2011. Disponível em: <http://cetic.br/usuarios/tic/2011-total-brasil/ > . Acesso em 10/07/2015.

TIC LANHOUSES 2010. São Paulo: Comitê Gestor da Internet no Brasil. 2010. Disponível em: <http://op.ceptro.br/cgi-bin/ind icadores-c gibr-ticlanhouse2010? pais=brasil\&estado=rj\&academia=academia\&age $=$ de $-16-a-24-$ anos\&education $=$ superior $\&$ purpose $=$ pesquisa-academica $>$. Acesso em 10/07/2015.

CHARNEY, Evan. Political Liberalism, Deliberative Democracy, and the Public Sphere. The American Political Science Review. Vol. 92. No. 1. Mar, 1998. PP. 97-110. Disponível em: $\langle$ http://www.jstor.org.ez24.periodicos.capes.gov.br/stable/2585931 >. Acesso em 10/07/2015.

CRAIDE, Sabrina. Para associação de empresas de TI, guarda de dados no país pode afugentar empresas. Brasilia: Agência Brasil. 31/10/2013. Disponível em: < http:/agenciabrasil.ebc.co m.br/no tic ia/2013-10-31/para-associa cao-de-empresas-de-ti-guard ade-dados-no-pais-pode-afugentar-empresas >. Acesso em 10/07/2015..

DE LUCA, Javier Augusto. Informática y delito: reunión preparatória del XIX Congresso Internacional de la Associación de Derecho penal - AIDP. $1^{\mathrm{a}}$ Ed. Ciudad Autónoma de Buenos Aires: Infojus. 2014.

ESTADÃO. A neutralidade necessária. 30/10/2013. Disponível em: < http://www.estadao.com.br/noticias/impresso,a-neutralidade-necessaria-, 1091251,0.htm>.

Acesso em 10/07/2015.

EXAME. Google apoia Marco Civil, mas rejeita data centers no país. 25/10/2013. Disponível em: <http://exame.abril.com.br/tecnologia/noticias/google-apoia-marco-civil-masrejeita-data-center-no-pais $>$. Acesso em 10/07/2015. .

FARACO, Alexandre Ditzel. Regulação e Direito Concorrencial: as telecomunicações. São Paulo: Livraria Paulista. 2003.

FERRAZ, Joana Varon; CABRAL, Antonio; MAGRANI, Eduardo. Pontos de Cultura e inclusão digital: estudo de caso em 4 Pontos de Cultura do país. In: FERRAZ, Joana Varon; LEMOS, Ronaldo. Pontos de cultura e lan houses: estruturas para inovação na base da pirâmide social. Rio de Janeiro: Escola de Direito da Fundação Getúlio Vargas. 2011.

FERRAZ, Joana Varon; LEMOS, Ronaldo. Pontos de cultura e lan houses: estruturas para inovação na base da pirâmide social. Rio de Janeiro: Escola de Direito da Fundação Getúlio Vargas. 2011.

FUNDAÇÃO GETÚLIO VARGAS. Centro de Tecnologia e Sociedade da Escola de Direito do Rio de Janeiro. Relatório de políticas de Intemet: Brasil 2011. São Paulo: Comitê Gestor da Internet no Brasil. 2012

FUNDAÇÃO GETÚLIO VARGAS. Centro de Tecnologia e Sociedade da Escola de Direito do Rio de Janeiro. Direitos autorais em reforma. Rio de Janeiro: FGV Direito Rio. 2011 
GAZZARRINI, Rafael. Garota do video íntimo "do WhatsApp" fala sobre a polêmica. Curitiba: TecMundo.com.br. 23/10/2013. Disponível em: $<$ http://www.tecmundo.com.br/Internet/46079-garota-do-video-intimo-do-whatsapp-falasobre-a-polemica.htm>. Acesso em 10/07/2015. .

GHOSH, Shikhar. Making business sense of the Internet. Harvard Business Review. Vol. 76, No. 2 Março-Abril, $1998 . \quad$ Disponível $<$ http://go.galegroup.com.ez24.periodicos.capes.gov.br/ps/i.do?id=GALE\%7CA20496574\&v $=2.1 \& \mathrm{u}=$ capes $58 \& \mathrm{it}=\mathrm{r} \& \mathrm{p}=\mathrm{AONE} \& \mathrm{sw}=\mathrm{w}>$. Acesso em 10/07/2015.

GROSSMANN, Luís Osvaldo. Para teles, neutralidade de rede prejudica modelos de negócios. [S.L.]: ConvergenciaDigital.uol.com.br. 30/08/2012. Disponível em:


LYyRA6wsU>. Acesso em 10/07/2015. .

HABERMAS, Jünger. Três modelos normativos de democracia. Lua Nova: revista de Cultura e Política. N $\mathrm{N}^{\circ}$. 36. São Paulo. 1995. Disponível em: $\langle$ http://www.scielo.br/scielo.php?script=sci_arttext\&pid=S0102-64451995000200003 >

Acesso em 10/07/2015..

HARRAS, Georges; SORNETTE, Didier. How grow a bubble: a model of myopic adapting agents. Journal of Economic Behavior and Organization. Vol. 80, $\mathrm{n}^{\circ}$ 1. Setembro, 2011. P. 137-152. Disponível $\langle$ http://dx.doi.org.ez24.periodicos.capes.gov.br/10.1016/j.jebo.2011.03.003>. Acesso em $10 / 07 / 2015$.

HOPSTEIN, Graciela. O Programa Cultura Viva e os Pontos de Cultura: a constituição de uma rede democrática de produção político-cultural. In: FERRAZ, Joana Varon; LEMOS, Ronaldo (Coordenadores). Pontos de Cultura e Lan houses: estruturas para a inovação na base da pirâmide social. Rio de Janeiro: Escola de Direito do Rio de Janeiro da Fundação Getúlio Vargas. 2011.

INDEPENDENT, The. Google chief: My fears for Generation Facebook. 18/08/2010. Disponível em: <http://www.independent.co.uk/life-style/gadgets-and-tech/news/googlechief-my-fears-for-generation-facebook-2055390.html>. Acesso em 10/07/2015

KRAUT, Robert; KIESLER, Sara; BONEVA, Bonka; et alter. Internet Paradox Revisited. Journal of Social Issues. Vol. 58. $\mathrm{N}^{\mathrm{o}}$ 1. 2002. PP. 49-74. Disponível em: $<$ http://onlinelibrary.wiley.com.ez24.periodicos.capes.go v.br/doi/10.1111/1540$\underline{4560.00248 / \mathrm{pdf}>}$. Acesso em 10/07/2015.

LEMOS, Ronaldo. Introdução - Farol Digital: Pontos de Cultura e lan houses como centros de inclusão digital. In: FERRAZ, Joana Varon; LEMOS, Ronaldo (Coordenadores). Pontos de Cultura e Lan houses: estruturas para a inovação na base da pirâmide social. Rio de Janeiro: Escola de Direito do Rio de Janeiro da Fundação Getúlio Vargas. 2011.

MENDES, Gilmar Ferreira; BRANCO, Paulo Gustavo Gonet. Curso de Direito Constitucional. $7^{\text {a }}$ Ed. São Paulo: Saraiva. 2012.

MORAES, Maurício. Marco Civil: dados em servidores nacionais garantem privacidade? São Paulo: BBC $\quad$ Brasil. 30/10/2013. Disponível em: 
<http://www.bbc.co.uk/portuguese/noticias/2013/10/131030_marco_civil_mm_dg.shtml>.

Acesso em 10/07/2015..

OLIVEIRA, Patrícia Cerqueira de. Risco Sistêmico. In: PORTO, Antônio José Maristrello; GONÇALVES, Antônio Carlos Porto; SAMPAIO, Patrícia Regina Pinheiro (Coordenadores). Regulação financeira para advogados. Rio de Janeiro: Elsevier e FGV. 2012.

OTTONI, Alexandre; PAZOS, Deive et al. NerdCast $\mathbf{n}^{\mathbf{0}}$ 320: A Cultura da Internet . [Curitiba]: Ig.com.br. 20 de julho de 2012. Disponível em: $<$ http://jovemnerd.ig.com.br/nerdcast/nerdcast-320-a-cultura-da-Internet/ $>$. Acesso em $10 / 07 / 2015$.

PORTO, Antônio José Maristrello. Introdução: especulações, apostas irresponsáveis e a crise financeira de 2008. In: PORTO, Antônio José Maristrello; GONÇALVES, Antônio Carlos Porto; SAMPAIO, Patrícia Regina Pinheiro (Coordenadores). Regulação financeira para advogados. Rio de Janeiro: Elsevier e FGV. 2012.

POSNER, Richard Allen. The crisis of capitalist democracy. $1^{\mathrm{a}}$ Ed. Cambridge: Harvard University Press. 2010.

Sobre o recebimento da medalha Ronald H. Coase: incerteza, a crise econômica e o futuro do direito e economia. In: PORTO, Antônio José Maristrello; GONÇALVES, Antônio Carlos Porto; SAMPAIO, Patrícia Regina Pinheiro (Coordenadores). Regulação financeira para advogados. Rio de Janeiro: Elsevier e FGV. 2012.

REUBER, Allison Rebecca; FISCHER, Eileen. International entrepreneurship in Internetenabled markets. in: Journal of Business Venturing, Vol. 26, $\mathrm{n}^{\circ}$ 6. Novembro, 2011, PP. 660$679 . \quad$ Disponível em: <http://dx.doi.org.ez24.periodicos.capes.gov.br/10.1016/j.jbusvent.2011.05.002>. Acesso em 10/07/2015.

ROBLES, José Manuel. La democracia deliberativa y la deliberación digital. El caso de QOT. In: IDP. Revista de Internet, Derecho y Política, Barcelona, $\mathrm{n}^{\circ}$ 7, sep. 2008. Disponível em: <http://idp.uoc.edu/ojs/index.php/idp/article/view/n7-robles $>$. Acesso em 10/07/2015.

SCHERKERKEWITZ, Iso Chaitz. Direito e Internet. $1^{\text {a }}$ Ed. São Paulo: Revista dos Tribuna is. 2014.

SEN, Amartya. Development as Freedom. 1 ${ }^{\text {a }}$ Ed. New York: Alfred A. Knope, Inc. 2000.

TECHDIRT. Brazil's Marco Civil not dead yet; Yahoo voices support. 01/05/2013. Disponível em: $\quad$ http://www.techdirt.com/articles/20130430/03554022889/yahoo-announces-publicsupport-brazils-marco-civil.shtml>. Acesso em 10/07/2015..

TERRA. Marco Civil da Internet: Facebook teme mudanças na lei, diz deputado. [s.l.]: Terra.com.br. 24/10/2013. Disponível em: <http//tecnologia.terra.com.br/Internet/marco-civilda-Internet-facebook-teme-mudancas-na- lei-dizdeputado,fb869b437d9e1410VgnVCM5000009ccceb0aRCRD.html. Acesso em 10/07/2015. .

THE ECONOMIST. Economics A-Z terms. London: economista.com. [200-?]. Disponíve1 em: 〈http://www.economist.com/economics-a-to-z〉. Acesso em 10/07/2015. 
UN. UNCTAD. Information Economy Report: ICTs as an Enabler for Private Sector Development. New York e Genève: Nações Unidas. 2011. Disponível em: <http://unctad.org/en/PublicationsLibrary/ier2011_en.pdf >. Acesso em 10/07/2015.

VENCATESAN, Jayshree. Recent Initiatives in distance education. Current Science. Vol. 96, $\mathrm{n}^{\mathrm{o}}$ 7. Outubro, 2006. PP.891-893. Disponível em: <http://cstest.ias.ac.in/cs/Downloads/article_40525.pdf >. Acesso em 10/07/2015.

WACHOWICZ, Marcos. Propriedade intelectual do Software \& Revolução da tecnologia da informação. $1^{\text {a }}$ Ed. Curitiba: Juruá. 2010.

WU, Tim. Network Neutrality, Broadband Discrimination. Journal of Telecommunications and High Technology Law, Vol. 2, 2003, p. 149. Disponível em: $\langle$ http://ssrn.com/abstract=388863 $>$. Acesso em 10/07/2015. 